\section{Imaging the dissected aorta}

SIR,-I read with interest and sympathy $\mathrm{Mr}$ Treasure's editorial on imaging the dissected aorta. ${ }^{1} \mathrm{I}$ agree that it is a difficult to achieve a standard approach. I have found the following guidelines for acute dissection clinically reliable:

(a) Type B dissection is defined as dissection confined to the descending aortathat is, any part of the aorta beyond the origin of the left subclavian artery.

(b) Type A dissection is any dissection that involves the ascending aorta, whether or not it also affects the descending aorta, and irrespective of the site of entry.

(c) Computed tomography (CT) is a reliable technique for the detection and assessment of type B dissections. It is certainly more reliable than angiography. This is because the flap in type $B$ dissections is usually static and can be reliably imaged by $\mathrm{CT}$, despite the fact that the true lumen may have regained a smooth, circular cross section.

(d) In type A dissection the flap in the ascending aorta is often mobile, giving a significant incidence of false negative CT examinations, but nevertheless ...

$(e)$ the ascending aorta is always dilated in type A dissection. If a dissection in the descending aorta is accompanied by an ascending aorta of normal size it is reasonable to exclude type A origin or extension of the false lumen.

In passing, I would like to endorse the efficacy of transoesophageal sonography in the diagnosis of traumatic aortic tear, as described by de Belder et al..$^{2}$ Indeed, I have yet to hear of a falsely negative study.

JB PARTRIDGE Harefield Hospital,
Harefield,

Harefield,
Middlesex UB9 $6 \Im H$

1 Treasure $\mathrm{T}$. Imaging the dissected aorta. $\mathrm{Br}$ Heart $f$ 1993;70:497-8.

2 de Belder A, Thomas $M$, Marrinan, $M$. Traumatic rupture of the thoracic aorta diagnosed by transoesophageal echocardiography. Br Heart $\mathcal{F}$ 1993;70:393-4.

This letter was sent to the author, who replies as follows:

SIR,-Dr Partridge's guidelines indicate his keen interest in this problem and that he has considered it carefully. I will address his points item by item.

( $a$ and $b$ ) In the original paper on which the Stanford classification is based ${ }^{1}$ type $B$ is defined as dissection that does not extend proximally to the subclavian artery. In a subsequent paper there was a subtle but important change in detail. ${ }^{2}$ Type A includes any dissection that involves the ascending aorta, just as Dr Partridge writes, but type $B$ includes all the rest, thus including some cases with arch involvement. ${ }^{12}$

No classification is perfect but the virtue of the current version of the classification is that it defines a group (type A) in which a challenging but achievable operation on the ascending aorta protects the patient from three lethal consequences of dissection at this site:

- Rupture into the pericardium

- Severe aortic valvar regurgitation

- Occlusion of the coronary ostia

This reduces the risk from near $100 \%$ for type A to a much lower figure, made up of the risk of the operation itself and the risk associated with any residual uncorrected abnormality in the arch and descending aorta. Classification is an interesting discipline. In this instance type $A$ is defined by inclusion of the particular characteristicthat is, involvement of the ascending aorta - and type $B$ is defined by exclusion of this characteristic. ( $c, d$, and $e$ ) His observations on the nuances of the interpretation of computed tomograms of the ascending and descending aorta are nicely observed and ring true.

Although I had no data or experience on which to base a comment, I was worried when de Belder et al advocated transoesophageal echocardiography to diagnose a traumatic aortic tear. ${ }^{3}$ Dissection has length, so any cross sectional image will detect it. Traumatic aortic transection is a tear with an adjacent haematoma; it is not a propagating dissection. Because there are other sources of blood (rib and vertebral fractures) to cause the haematoma in trauma, it is visualisation of aortic wall discontinuity that is critical. High specificity, that is confidently excluding the diagnosis when it is absent, is required. We have argued elsewhere ${ }^{4}$ that the cross sectional image of CT cannot prove or exclude traumatic aortic dissection. In a critically injured patient this makes CT an unnecessary waste of time. The fact that transoesophageal echocardiography can be used at the bedside makes it attractive, provided a negative test is convincing and that any induced hypertension and local interference do not make the aorta go "pop".

$$
\begin{aligned}
& \text { TOM TREASURE } \\
& \text { Cardiac Department, } \\
& \text { St George's Hospital, } \\
& \text { Blackshaw Road, } \\
& \text { London SW17 OQT }
\end{aligned}
$$

1 Daily PO, Trueblood HW, Stinson EB, Wuerflein RD, Shumway NE. Management of acute aortic dissections. Ann Thorac Surg 1970;10:237-47.

2 Miller DC, Stinson EB, Oyer PE, Rossiter SJ, Reitz BA, Griepp RB, Shumway NE. Operative treatment of aortic dissections. $\dot{f}$ Operative treatment of aortic dissection
Thorac Cardiovasc Surg 1979;78:365-82.

3 de Belder A, Thomas $\mathbf{M}$, Marrinan $\mathbf{M}$ Traumatic rupture of the thoracic aorta diagnosed by transoesophageal echocardiography. Br Heart f 1993;70:393-4.

4 Unsworth-White MJ, Buckenham T, Treasure T. Traumatic rupture of the thoracic aorta-computed tomography may be a dangerous waste of time. Ann $R$ Coll Surg Engl (in press)

\section{Anthracyclines and the heart}

SIR,-I thank Dr Rhoden, Dr Hasleton, and Dr Brooks for an excellent review of anthracyclines and the heart. ${ }^{1}$

I would like to point out an error. The evidence for doxorubicin-related cardiotoxicity involving myocardial adrenergic derangement comes from ${ }^{123}$ I-meta-iodobenzyl-guanidine (MIBG) rather than from ${ }^{123}$ I-methoxy-isobutyl isonitrile (MIBI). ${ }^{2}$ These radiopharmaceuticals are quite dissimilar. MIBG shares similar uptake mechanisms into sympathetic nerve endings as noradrenaline. It is therefore ideally suited to imaging both the distribution of sympathetic nerve endings in the heart as well as neuroendocrine tumours such as pheochromocytomas. ${ }^{34} \mathrm{MIBI}$ is a myocardial perfusion agent available in cold kit form that is labelled with technetium-99m rather than with iodine-123. MIBI is a lipophilic agent taken up into myocytes independently of the sympathetic nerve endings but roughly proportionally to myocardial blood flow. MIBI is therefore used to assess the patency of coronary arteries rather than the status of the sympathetic nervous system. ${ }^{5}$

$$
\begin{array}{r}
\text { PAUL THOMAS } \\
\text { Department of Nuclear Medicine, } \\
\text { fohn Hunter Hospital, } \\
\text { Locked Bag 1, } \\
\text { Newcastle Mail Centre, } \\
\text { NSW 2310, }
\end{array}
$$

Australia

We thank Dr Thomas for drawing attention to this error and we apologise to the authors of the review for introducing this mistake when the technical editor mistook the abbreviation MIBG for MIBI. Author can help us to avoid such mistakes by spelling out all abbreviations and acronyms at the first mention-EDITOR

1 Rhoden W, Hasleton P, Brooks N. Anthracyclines and the heart. Br Heart $\mathscr{f}$ 1993;70:499-502.

2 Valdes-Olmos RA, Ten Bokkel-Huinuk WW, Greve JC, Hoefnagel CA. ${ }^{123}$ I-MIBG and serial radionuclide angiocardiography in doxorubicin-related cardiotoxicity. Clin Nucl Med 1992;17:163-7.

3 Dae M. Scintigraphic assessment of cardiac innervation using iodine-123 metaiodobenzylguanidine. In: Ernst $E$ van der Wall, Sochor H, Righetti A, Niemeyer MG, eds. What's new in cardiac imaging? Dordrecht: Kluwer Academic Publishers, 1992;377-85.

4 Gross MD, Shapiro B, Thrall JH. Adrena scintigraphy. In: Gottschalk A, Hoffer PB, Potchen EJ, eds. Diagnostic nuclear medicine, Baltimore William and Wilkins, 1988;826-7.

5 Rigo P, Larock M, Braat SH. Myocardial perfusion imaging with technetium- $99 \mathrm{~m}$ isonitriles: Attractive thallium substitutes? In Ernst E van der Wall, et al eds. What's new in cardiac imaging? Dordrecht: Kluwer

Balloon dilatation (valvoplasty) as first line treatment for severe stenosis of the aortic valve in early infancy: median term results and determinants of survival

SIR,-In their otherwise excellent article Bu'Lock and her colleagues' do not give any details of the morphology of the aortic valve itself, specifically the number of leaflets. This matter is of importance because in the so-called unicommissural and unicuspid variant of aortic valvar stenosis recent studies have shown that the leaflet tissue is attached within the aortic root in a circular rather than a semilunar fashion. ${ }^{2}$ This arrangement would seem, on morphological grounds, to militate against successful balloon dilatation: but morphologists are constantly wary of predicting outcomes in life from their observations on cadaveric hearts. For this reason it would be invaluable to know whether Bu'Lock and her colleagues had information on the number of leaflets present in the valves dilated in their patients?

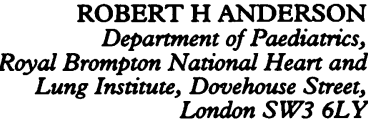

1 Bu'Lock FA, Joffe HS, Jordan SC, Martin RP Balloon dilatation (valvoplasty) as first line treatment for severe stenosis of the aortic valye in early infancy: medium term result valve in early infancy: medium term results and determinan

2 McKay $R$, Smith A, Leung MP, Arnold $R$ Anderson RH. Morphology of the ventriculoaortic junction in critical aortic stenosis. $f$ Thorac Cardiovasc Surg 1992;104:434-42. 